\title{
Cycling and designing for cyclists in Germany: Road safety, Guidelines and Research
}

\author{
Benjamin Schreck \\ Federal Highway Research Institute (BASt) \\ Bergisch Gladbach, Germany \\ schreck@bast.de
}

ABSTRACT: Cycling is considered a social, ecofriendly, pollution-free, low noise and healthy activity and mode of transportation. The socially and political$l y$ desired increase of attractiveness and promotion of cycle traffic is expected to shift the modal split towards non-motorized traffic. This could contribute towards a more environment-friendly mobility. There are currently around 70 million bicycles including 2.5 million electrically assisted bicycles (pedelecs) in Germany. This number is expected to increase in the near future with greater use of electromotive assisted bicycles. The changes in cycle use, the increasing use of electrically assisted cycles and raised specific requirements e.g. on quality of traffic flow will require modifications to infrastructure in terms of cycle planning, cycle conception, road construction and maintenance.

This article presents an overview and selected current topics in the field of road safety based on German national accident statistics. The data will be compared with the accident statistics of other European countries. In this context of high accident numbers, high accident severity, and the rising share of bicycle accidents, it will be necessary to initiate further and more effective interdisciplinary research activities. Otherwise the development of cycling safety might become decoupled from the positive improvements in overall traffic safety. Following a general summary of guidelines for road design and cycling facilities, this article shows the development of interdisciplinary research activities and offers an extract of the current and completed cyclist safety research projects in the areas of behaviour, infrastructure, safety equipment and vehicle technology in Germany.

KEY WORDS: Accidents, Cycle traffic, Design Guidelines, Interdisciplinary Research, Safety Programm.

\section{INTRODUCTION}

"Joining forces to evolve cycling" is the title of the 2020 national cycling plan (NRVP) issued by Germany's Federal Ministry of Transport and Digital Infrastructure (BMVI). NRVP 2020 lays out the strategies and individual action areas through which cycling is to be developed and improved in Germany. Among others, these action areas include cycle transportation planning and concepts, infrastructure, traffic safety and electromobility (BMVI 2012).

A shift to cycling as a share of transportation methods, the growing use of electrically assisted cycles (pedelecs), as well as improved linkages with other means of transportation (amongst others public transport) are expected to contribute substantially to an environmentally-sound mobility. However, demands on infrastructure by users and travel demand are becoming increasingly differentiated. Children, seniors, commuters, recreational cyclists, pedelec users or cycle tourists all prefer a direct route without detours, just as pedestrian traffic does. The difficulty lies in the fact that these "inhomogeneous" road users travel either in their own designated lanes or paths or spaces shared with pedestrians alongside lanes with moving or standing motor vehicle traffic. This results in great challenges for cycling transportation planning and conceptualization as well as road construction or maintenance.

A future strategic subject are cycling superhighways or cycling super connectors which link important high-potential origin and destination areas in the cycling route networks of a municipality or a city-suburban region over longer distances. Cycling superhighways are at the top of the agenda both domestically and internationally. 
In the context of (increasing) cycle ridership as well as heightened demands for traffic quality and travel speeds, more attention on traffic accidents involving cyclists is also called for. In the year 2015, 78,142 cyclists were injured in accidents in total, including 383 fatalities and 14,224 seriously injured cyclists (according to official German traffic accident statistics (Federal Statistical Office 2016)). These numbers included 36 fatally injured and 871 seriously injured riders of the pedelec 25 (with an electric pedal assist up to $25 \mathrm{~km} / \mathrm{h}$ ).

The target of the 2011 Traffic Safety Programme is to enhance road safety and reduce the number of all road fatalities in Germany by $40 \%$ by 2020 (BMVI 2015). The programme is based on the European Commission's "policy orientations on road safety 2011-2020". The potential impact on the number of cyclist fatalities was also demonstrated by the 2015 mid-term review (BMVI 2015) of the BMVI's 2011 Traffic Safety Programme. But if this potential is to be realized, the systematic application of current technical guidelines, the design for cycling facilities, the improvements to existing infrastructure and in traffic participant behaviours are required. Cycling therefore needs to receive a stronger focus in traffic safety studies than has been the case to date.

\section{CYCLE TRAFFIC - FACTS AND POTENTIALS}

\subsection{Cycle stock}

Cycle ownership numbers have remained nearly unchanged since the mid-1990s. The Mobility in Ger- many (MiD) survey for both 2002 and 2008 counted roughly 70 million operable cycles in private households. $81 \%$ of private households had at least one cycle (vs. $75 \%$ in 1993), with $25 \%$ owning three or more (Huetter 2013).

The stock of pedelecs 25 and E-Bikes has been rising steadily since 2008 and in 2014 reached slightly more than 2.5 million vehicles. More than $95 \%$ of the latter are pedelecs 25 with an electric pedaling assist up to $25 \mathrm{~km} / \mathrm{h}$ and a maximum nominal continuous output of 250 watt. E-bikes are vehicles that can be driven at speeds of 20,25 , or $45 \mathrm{~km} / \mathrm{h}$ using an electric powertrain shifted with a twist grip or control button even without the rider simultaneously pushing the pedals. Also to be found in the electromobility sector is the pedelec 45 or S-pedelec, with rider pedaling assist to $45 \mathrm{~km} / \mathrm{h}$ and a nominal continuous output of maximum 500 watt.

\subsection{Mobility and cycling}

Day-to-day mobility in Germany is quantified by the MiD survey. Studies on mobility and vehicle usage show different bicycle use patterns depending on age (see Figure 1). In the year 2008 nearly $20 \%$ claimed to be using the bicycle daily and another $20 \%$ more times per week. In general we can see a higher usage for younger people and lower use for older people (INFAS and DLR 2010).

The current MiD 2016 survey will be conducted in 2016 - 2017. One important reference value determined by the MiD that permits making statements

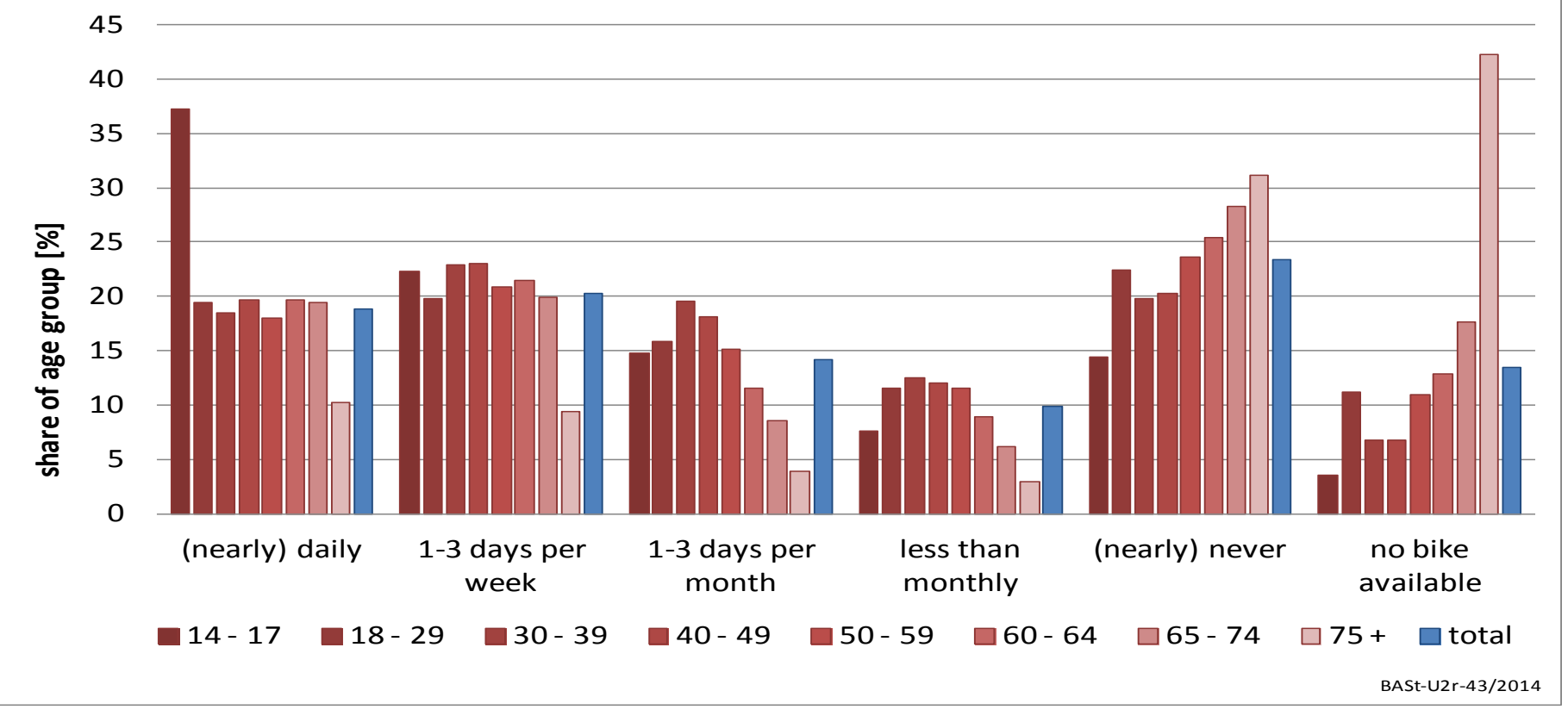

Figure 1: Use of bicycle by age groups (INFAS and DLR 2010). 
about the importance of cycle traffic as a transportation type is the modal split. Modal split shows the percentages per type of transportation used for all trips (choice of transportation means). Differences in modal split are evident by federal state, municipality, and city as well as by trip purpose, population group, age group, gender, vehicle availability, etc. Figure 2 depicts the cycling traffic percentage in the modal split for the years 2002 and 2008 by federal state. The modal split of cycle traffic shows only a slight growth from $9 \%$ to $10 \%$. However, a markedly stronger rise can be seen in some individual states, while in others a reduction of the cycling percentage is apparent. Furthermore, with respect to the development of the modal split for Germany from 1976 to 2008, cycling does not exhibit any solid trend (Follmer 2011). Still, the NRVP 2020 envisions $15 \%$ growth by 2020 in the proportion of cycling for all trips travelled in Germany (BMVI 2012).

$90 \%$ of all cycle trips cover distances of less than $5 \mathrm{~km}$. In terms of the modal split percentage differentiated for distances covered by cycle traffic, it clearly emerges that riding less than $1 \mathrm{~km}$ accounts for $14 \%$, from $1 \mathrm{~km}$ to less than $2 \mathrm{~km}$ for $18 \%$, and from $2 \mathrm{~km}$ to less than $5 \mathrm{~km}$ for $11 \%$. From $5 \mathrm{~km}$ to less than $10 \mathrm{~km}$, cycling garners a $5 \%$ share and from $10 \mathrm{~km}$ and up it is minimal. The main purpose of cycling at over $50 \%$ is leisure time use. Other trip purposes ranging from $7 \%$ and $15 \%$ are work, shopping, errands, and school (Follmer et al. 2004; Follmer et al. 2010).

\subsection{Cycling potentials}

The potential for promoting cycling in order to increase the intra-urban cycling percentage for climate protection as well as for the growing use of pedelecs and their impact on the environment has been quantified in detail. As part of the study "Cycling's potential in urban traffic" (Baier et al. 2013), a before-after comparison of various method concepts and scenarios was carried out using a macroscopic traffic model. This methodology permits an evaluation at the level of means (without effects of steps taken in parallel) and hence theoretical analyses of traffic-related and environmental impacts. Using a three-city sample with different initial assumptions and constraints, the study quantified the effectiveness of measures such as the adaption of the existing cycling facilities to the current guidelines or of more discrete steps such as the establishment of cycling boulevards or cycling promotion campaigns.

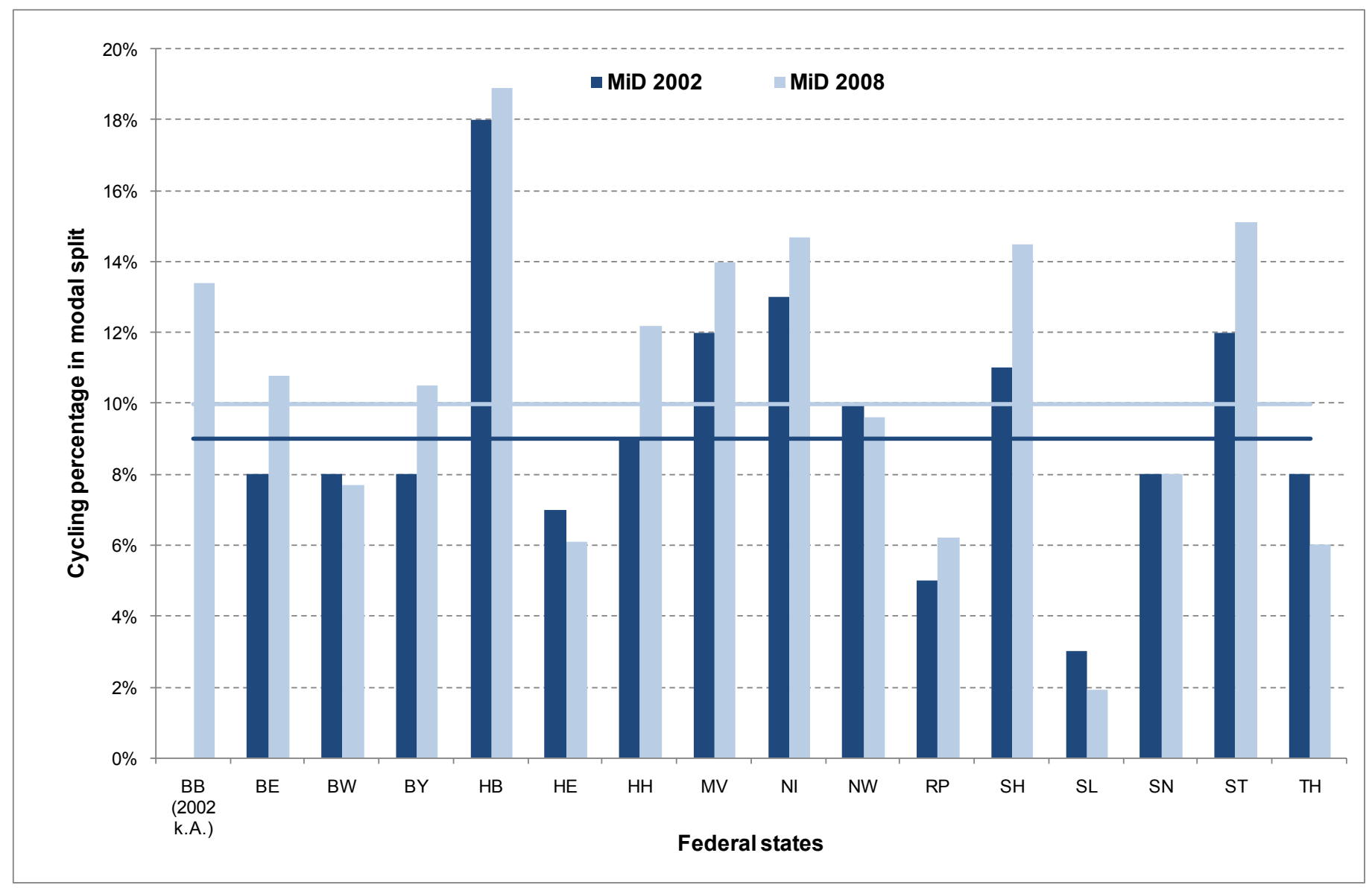

Figure 2: Modal Split by federal states and federal average (Follmer et al. 2004; Follmer et al. 2010). 
It turns out (see Figure 3) that the proposed measures were able to bring about a decline in the MIV (motorized individual vehicles) percentage with a concomitant rising share for cycling. The scenario of "soft and hard measures" comprises an upgrading of existing cycling facilities to the actual technical guidelines with integration of cycling promotion campaigns. The locally-set measure "bicycle-street or cycling boulevard" that builds on it only effects a minimal reduction of the MIV share and corresponding rise in cycling's share. Other scenarios evaluated, such as the use of pedelecs, yielded high potentials even in the presence of difficult topographies. The reduction in emissions basically tracks the reduction in MIV driving mileage. Moreover, the calculated scenarios with respect to noise emission showed only a small effect (Baier et al. 2013). The framework methodology employed for the project, however, only allows analyzing highly delimited theoretical scenarios with fixed assumptions.

To summarize, we see that cycling's small share of the total trip volume goes hand in hand with a use for relatively short trips. One option for extending the trip lengths or heightening the attractiveness of the cycle for difficult topography, for instance, is offered by pedelecs. However, here consideration must be given to traffic type characteristics of cycling, such as the use over the course of a year, the age structure, and regional differences.

\section{CYCLING SAFETY - OVERVIEW AND SELECTED TOPICS}

Cyclists belong to the group of unprotected road users. Protective gear will only go so far in passively

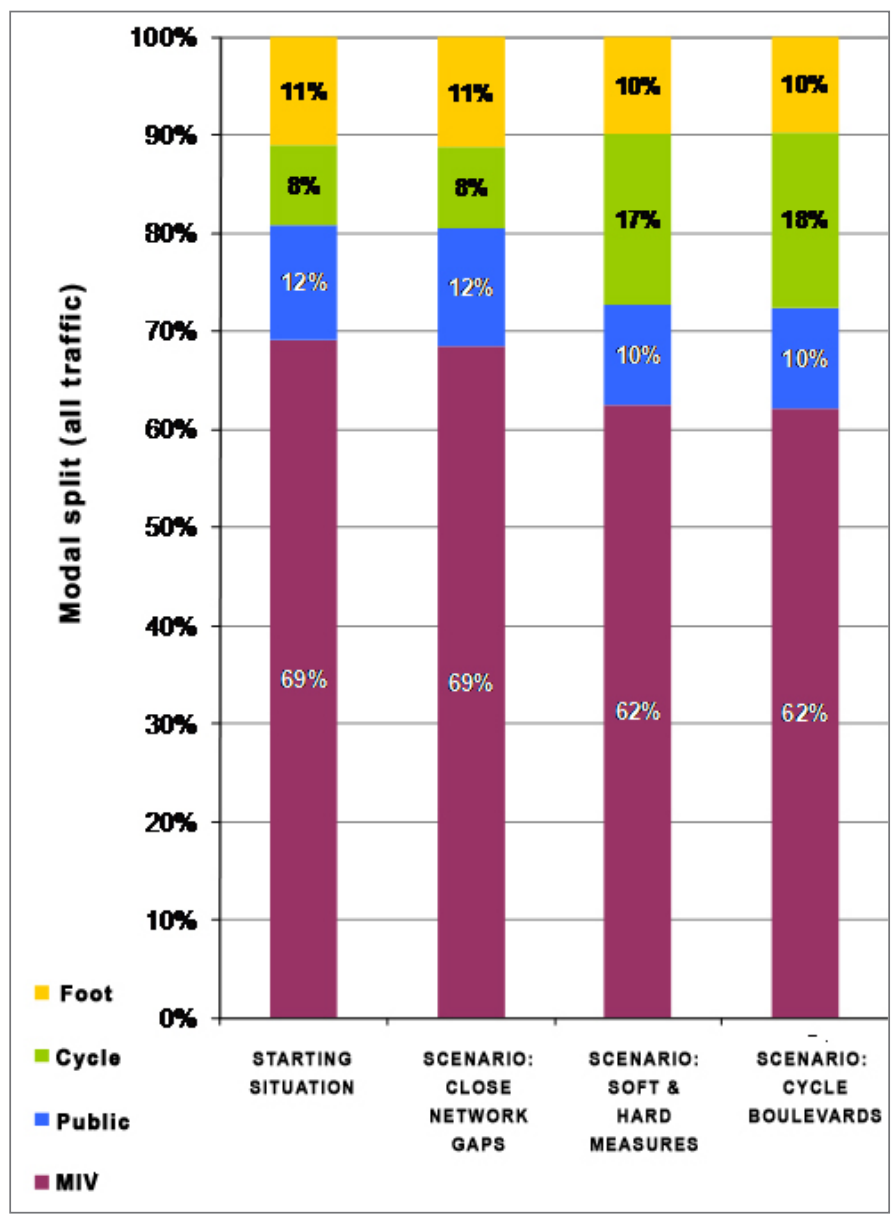

Figure 3: Modal splits for different scenarios; sample city Moenchengladbach (Baier et al. 2013).

protecting them against injury from accident. In case of cycle single accidents due to deficient infrastructure or rider error, as well as in collisions with other road users (cars or trucks, but also other cyclists, pedestrians, etc.), the consequences of accidents, even at relative low speeds, are often more serious for cyclists than for other road users.

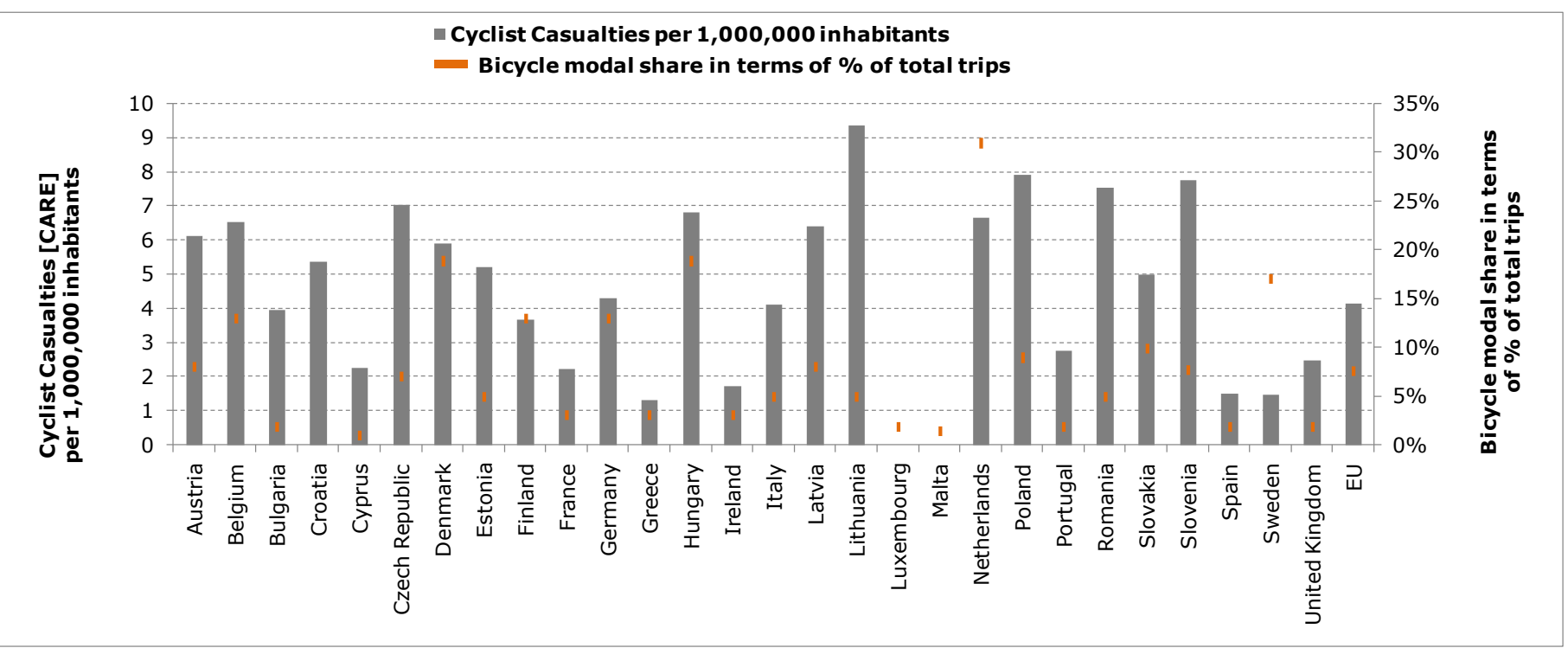

Figure 4: Bicycle modal share and cyclist causalities per 1,000,000 inhabitants (Data: European Commission). 
In the year 2013, around 2,000 cyclists were killed in road accidents in the 28-European countries (Data: European Commission). For comparison: in 2013354 cyclists were killed in road accidents in Germany which represented $11 \%$ of all road fatalities, according to the official traffic accident statistics (Federal Statistical Office 2014). Obviously, there is a big international variation in cyclist modal share and traffic accidents with cyclists. Figure 4 shows cyclists' fatalities per one million inhabitants and the bicycle modal share in terms of total trips for the countries of the European Union. The bicycle modal share in terms of total trips is $8 \%$ in the European countries. There are, however, also several cities with bicycle modal share over $40 \%$.

\subsection{Development of cycling accidents in Germany}

Traffic safety for cyclists within urban settings is in the focus of traffic safety work because of its high proportion of all fatalities and severely injured persons. A detailed look at how the accident numbers have developed shows that by the year 2014 the total number of all accidents involving personal injury (abbreviated in what follows as "U(P)") had dropped by about $15 \%$ from the year 2000 to $245,470 \mathrm{U}(\mathrm{P})$. By contrast, the number of cycling accidents with personal injury (year 2000 with 66,003 U(P)) rose by $8 \%$ during the same period (see Figure 5 ). The developments of road accidents with cyclists and injured cyclists suggest that users of bicycles have not benefited from traffic safety improvements in the same way than other road users have in the last nearly 15 years. In this regard, research should consider examinations in various areas (e.g. behaviour, infrastructure, and safety equipment/vehicle technology). The cyclist safety research should also focus on increasing the use of pedelecs and older cycle users.

The positive trend manifested since 2000 in accidents overall can also be observed in the number of accident casualties. The number of accident casualties in urban areas starting from the year 2000 (302,627 casualties) decreased by $16 \%$. However, over the same time, a $9 \%$ increase from 65,245 registered in the year 2000 occurred in the number of cyclists in accidents.

The number of accident casualties with severe and serious injuries was reduced in urban areas from 2000 to 2014 by $25 \%$. The reduction for the severely injured amounted to $23 \%$ (2000: 35,109 severely injured); for fatalities, it was $54 \%$. The number of fatalities dropped from 1,829 in 2000 to 983 in 2014. Once more, the development in the number of cyclists involved in accidents shows up as less positive. Thus, from 2000 to 2014, a decrease of only about $5 \%$ registered in the most-serious and seriously injured categories. The drop in seriously injured cyclists amounted only to $4 \%$ (2000: 12,585 seriously

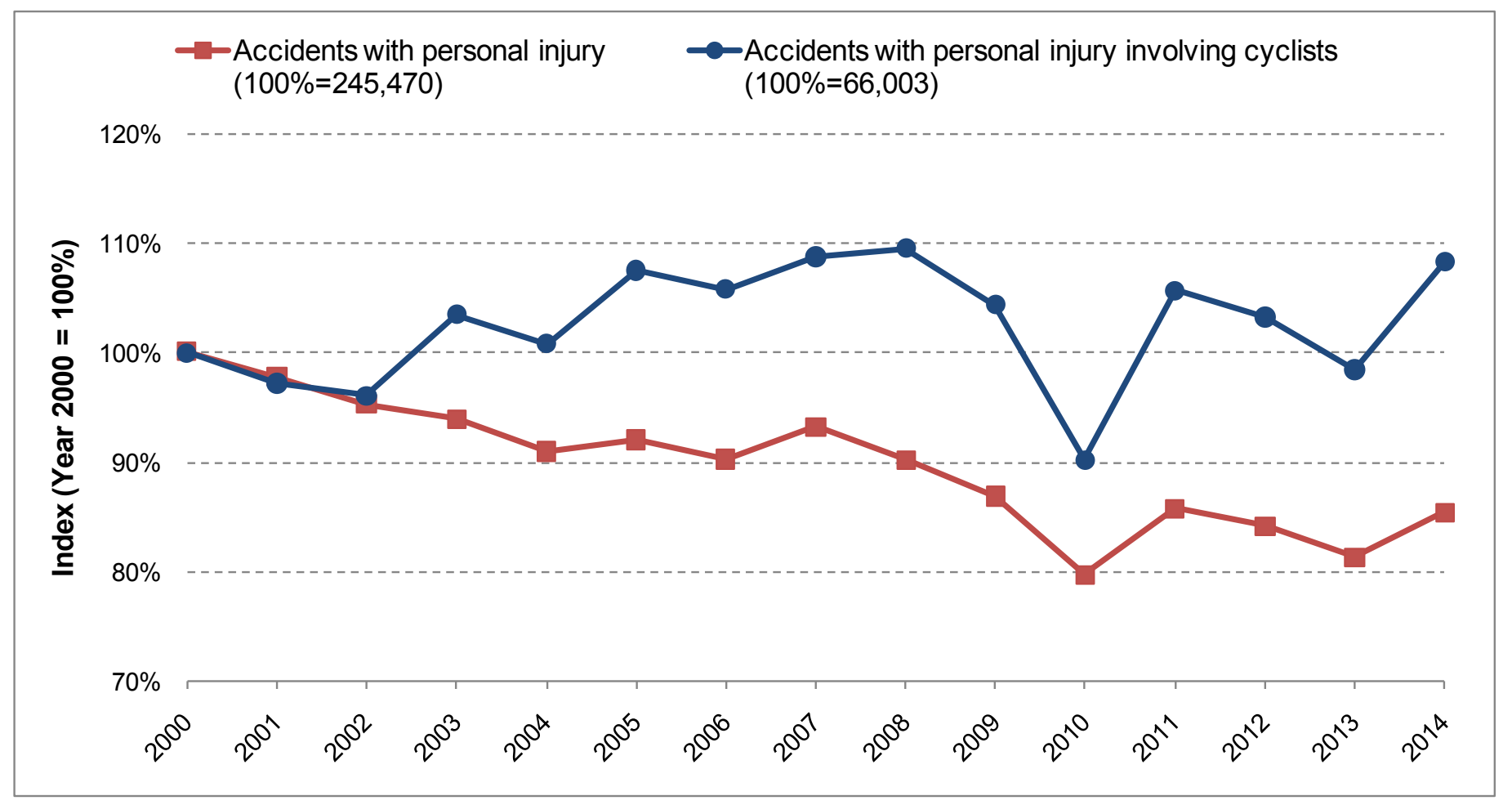

Figure 5: Development of accidents resulting in personal injury overall and accidents involving cyclists that resulted in personal injury for the period 2000 to 2014 (in built-up areas) (Data: Federal Statistical Office). 
injured); for cyclists killed it was 38 \% (2000: 327 cyclists killed.)

The ratio of cycling fatalities to all fatalities in urban locales is thus climbing continually. In 2014, cycling fatalities already amounted to $23 \%$ of all fatalities (compared to $20 \%$ in 2000). Cyclists were involved in a third of all accidents in built-up areas resulting in most-serious and serious personal injury. Here, close to half of all killed or seriously injured cyclists suffered accidents at junctions.

In 2014, according to the official road traffic accident statistics, a total of 8,033 cyclists suffered accidents outside of built-up areas respectively rural roads (autobahns excepted), with 172 fatalities and 2,551 seriously injured cyclists recorded. From 2000 to 2014, an overall reduction of $34 \%$ in accidents on secondary roads resulting in injury to people was achieved from 111,901 U(P) registered in 2000. Yet again, with respect to accidents involving cycles, only a $10 \%$ reduction could be recorded, from 7,919U(P) in 2000. The high number of cyclists killed on rural roads strongly calls for action.

\subsection{Characteristics of cycle accidents}

Accident consequences are more serious outside urban locales than within. Figure 6 shows the average annual number of intra-urban cycling accidents with personal injury for cycle-only accidents and by other parties involved in the accident. The most common other party in a cycling accident was a passenger car, followed by other cyclists and pedestrians. More than half of the accidents occurred due to turning off-conflicts or turning into- or crossing-conflicts. A large proportion of bicycle accidents also caused by the cyclists themselves are single vehicle accidents. Because of the number and severity of accidents, more detailed analyses should be planned for cycleonly accidents - also because of the high number of unreported cases. This applies regardless of the examined accident parties. Accident consequences are especially grave for cyclists involved in accidents with "heavy trucks".

Similar to motorcycle accidents, bicycle accidents are showing a typical seasonal distribution with higher numbers of accidents in summer and lower numbers in winter. In comparison to all other accidents, this seasonal effect is much more pronounced. This seasonal fluctuation leads to an increase in accident numbers in years which experienced early and warm spring months and late as well as warm and particularly dry autumn months.

Most of the bicycle accidents occur during the week. This is due to bicycles being mainly used for trips to work, school and shopping from Mondays through Fridays. The distribution over time shows high numbers of accidents in the morning and evening peak hours, which is consistent with the hours of high usage of bicycles. Looking deeper into the data, a higher share of accidents in the nighttime hours can also be found. This can be attributed to a higher

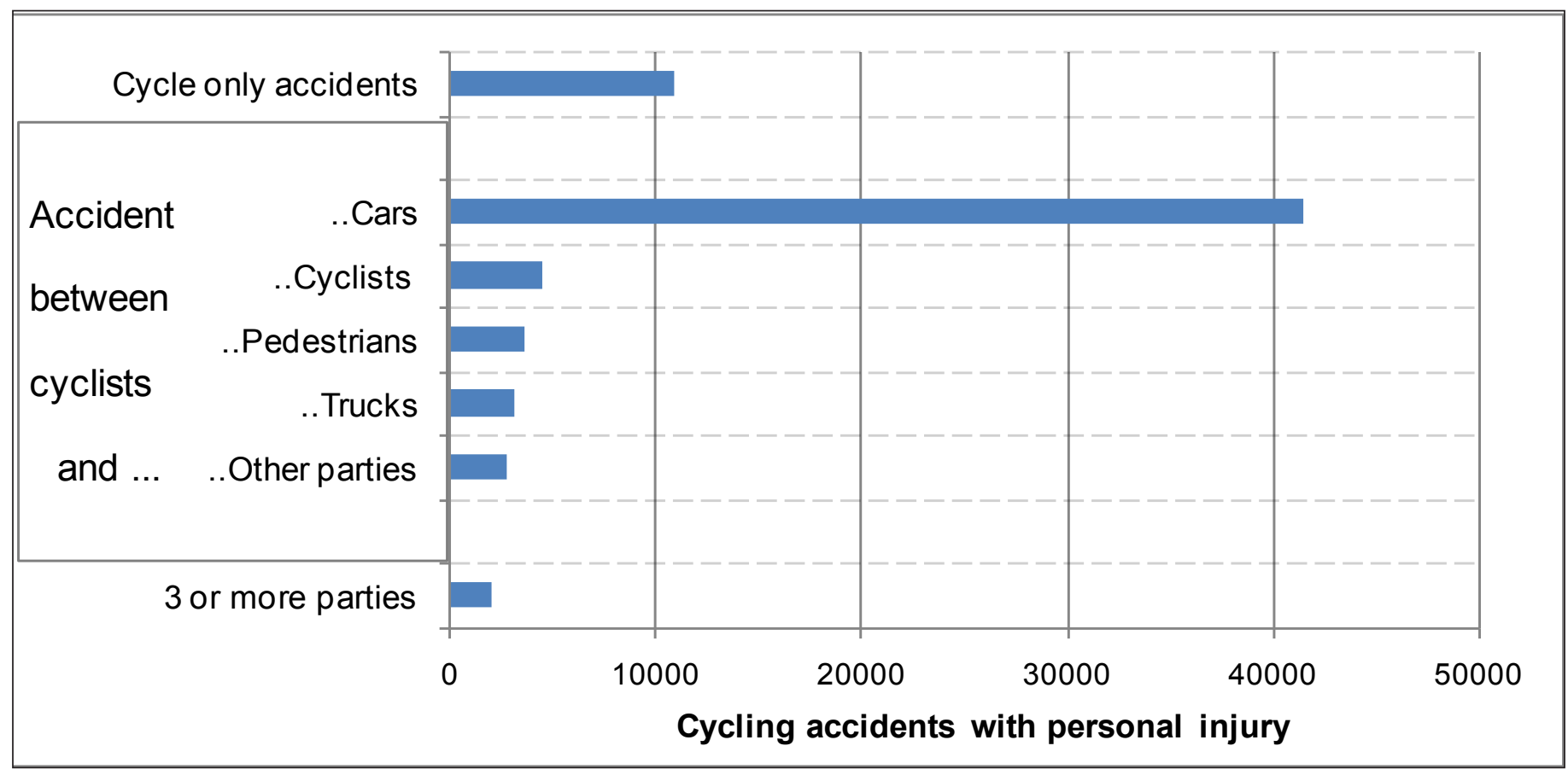

Figure 6: Annual average intra-urban cycling accidents with personal injury by cycle-only accident or other party involved (Data: Federal Statistical Office). 
risk for bicyclists in darkness and the preferred use of bicycles for leisure activities in the evening and nighttime hours, especially for younger people.

\subsection{Accidents between right turning trucks and cyclists}

Accidents between heavy trucks turning right and cyclists going straight ahead are often particularly serious. The situation between trucks and cyclists is critical especially because of visibility. In spite of the six mirrors that are mandatory for ensuring a maximum field of sight for the truck drivers, cyclists often cannot be seen or are not seen by the driver. Either the cyclist is overlooked or he is in a blind spot area resulting from the turning maneuver of the truck.

However, it is not possible to identify the number and severity of this accident situation in the German national road accident statistics because the conflict situation "blind spot" is not explicitly quantified. An extrapolation (Schreck and Poeppel-Decker 2014) for the year 2012 regarding the relevance of the conflict situation "blind spot" has been qualitatively examined to this purpose.

The extrapolation shows that around 640 injury accidents resulting in 23 fatalities and another 118 seriously injured cyclists are due to the accident situation between right-turning trucks and straight-riding cyclists. Thus, these accidents represent $1 \%$ of all bicycle accidents, and about $6 \%$ of cyclists killed. It became clear that "light" trucks, defined as vehicles weighing less than 7.5 tons permissible total weight, only slightly contribute to the serious accidents. In 549 collisions with "light" trucks, one cyclist was killed. $90 \%$ of the accidents with killed cyclists in "blind spot" situations are accidents with "heavy" trucks (more than 7.5 tons permissible total weight). Considering that on average about one cyclist is killed in every 10 injury accidents between a "heavy" truck and a cyclist in a "blind spot" situation, this proves the accident severity in terms of seriously or fatally injured cyclists to be much higher than in accidents of other traffic participants in other accident situations.

\section{DESIGN GUIDELINES - OVERVIEW AND DESIGN PRINCIPLES}

A basic requirement for achieving a high potential of cycling is to provide an appropriate, speedy and safe cycle infrastructure. Planning and design of safe infrastructure for cycling must be based on the latest state of the art.
In the year 2006 the German Road and Transportation Research Association (FGSV) published the Guidelines for the Design of Urban Roads 2006 (abbreviation: RASt 2006) and in the year 2012 the Guidelines for the Design of Rural Roads (abbreviation: RAL 2012). Both are dealing with bicycle facilities as part of the design of road sections and junctions. In addition the recommendations, especially for cycle facilities, (abbreviation: ERA) were published in 2010. Since the last ERA in 1995, research on cycling and cycling safety has been able to clarify essential questions which had been left unanswered regarding adequate cycling facilities and potential effects on road safety. The guidelines represent the current state of the technical knowledge. Safe and efficient cycle facilities are the basis for a good acceptance. Since the 1980s, safety research concerning cycling has been mostly conducted or commissioned by the Federal Highway Research Institute (BASt). New elements of cycling facilities were examined related to specific safety effects.

Subject of discussion as traffic-planning instruments, both domestically and internationally, are the concepts of cycling superhighways. These are intended to connect and link regions, city suburban regions and municipalities in better ways. Above all, the goals are increasing daily cycling traffic and especially the work trips.

The primary objective in the planning and design of urban roads in accordance with legal regulations is to balance the needs of users both among themselves and in relation to the adjacent uses (directly), which includes the improvement of road safety. RASt 2006

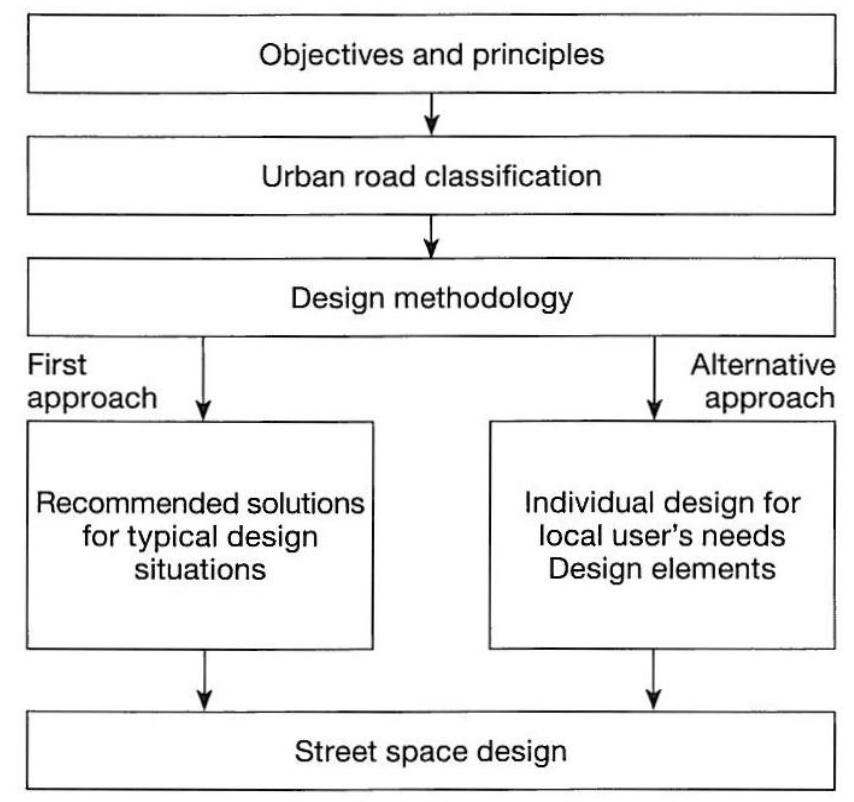

Figure 7: Structure of the guidelines for the design of urban roads (FGSV 2006). 
offers two methods with regards to the design process. Users of RASt 2006 can apply recommended solutions for typical design situations or an individualized street space design. The structure of the guidelines for the design of urban roads is shown in Figure 7. RASt 2006 includes the methods and tools for a better sharing of road space in the overall design of urban roads.

The RASt 2006 recommend, that planning and design of urban streets must be based on objectives derived from the liveability and viability of the towns and communities concerned. The objectives seek a balanced consideration of all claims for use of the local street space. In this process, it is frequently necessary - especially in urban centres - to reduce the volume, or at least the prioritisation, of individual motorised traffic in terms of speed and convenience in favour of pedestrians, cycle traffic, and local public transport. The 12 typical design situations in RASt 2006 cover 70 to 80 percent of the planning and design of urban roads in Germany.

ERA 2010 specifies RASt 2006 with images showing actual cross-section examples and figures relating to the design to encourage cycling. ERA 2010 provides the recommendations for planning, design, and operation of cycle facilities. The recommendations are divided into 12 chapters:

- Cycle traffic concepts

- Principles underlying the design

- Types of cycle facilities on urban streets

- Types of cycle facilities on urban junction

- Crossing facilities

- Cycling on access roads

- Cycling in opposition direction to one way roads

- Cycling in areas of pedestrian traffic

- Cycling on rural roads

- Off-street cycle facilities

- Construction and operation of bicycle facilities

- Effective control and quality assurance

The core content of ERA 2010 is to specify steps for a decision on the types of cycle facilities on urban roads. The selection process of the most appropriate cycle facilities is divided into the method:

- pre-selection of suitable forms of types of cycle facilities,

- verification of the feasibility,

- comparison of the appropriate types of cycle facilities.
The guidelines for rural roads (RAL 2012) are the basis for the design of safe and functional rural roads. The bicycle connections outside built-up areas are either through independent paths or on rural roads. On the latter, cyclists either use the road itself or separate cycling facilities next to the roadway. These are usually common foot and cycle paths for two-way bicycle traffic. The RAL 2012 specifies the requirements and limits for the selection of the independent path.

\section{RESEARCH ON CYCLING SAFETY OVERVIEW AND SELECTED TOPICS}

A series of studies by BASt and accident studies by insurers dealt and deal with the cycling issue complex. The areas of cycling research in the traffic safety context can be divided into the following individual research areas:

- Behaviour

- Infrastructure

- Safety equipment and vehicle technology

Research activities in the various research areas serve as the basis for regulations, sets of technical guidelines, standards and norms, as well as measures for traffic safety communication and call for attention to recommendations for developing cycle traffic with special emphasis on improving traffic safety. The interdisciplinary BASt research delves among others into the professional disciplines of traffic psychology, street planning and traffic flows. Active and passive vehicle safety on the domestic and international fronts are additional research subjects.

\subsection{The behaviour area}

The project titled "Traffic safety for cyclists: Analysis of safety-related motives, attitudes, and behaviours" provided a comprehensive, representative description of Germany's cycling population for the first time ever. It is common knowledge that there is a substantial unreported part of cycling accidents - especially for those involving slight injuries and only damages as well as for cycle-only accidents - so that many accidents are not reflected in the official road traffic accident statistics (see Figure 8). A survey was used to capture, among others, the use of bicycle, accident involvement, motives for use, and risk perceptions. In addition, a comprehensive analysis of cycling accidents was performed for one particular region in Germany. According to the study, special target 
groups are particularly youths and young adults, which distinguish themselves by high accident risk, and older cyclists whose heightened risk of injury in case of an accident makes them stand out from the total group. Some cyclist behaviours, which the subjects of the survey specifically mentioned, were identified in the present study as relevant to traffic safety. These include wrong utilization of the road (e.g. riding in the wrong direction on cycle paths and the illegal use of sidewalks), cycling under the influence of alcohol or while distracted by electronic devices. Among the measures addressed were, among others, more strongly thematizing or sensitizing to the risks of lapses in traffic safety communication and campaigns, reinforcing the monitoring and sanctioning of cyclists' misconduct, and implementing meaningful and safe cycling infrastructure facilities. In addition, it was found that injuries could be prevented or at least be reduced by the wearing of bicycle helmets. Through strengthening the positive depiction of bicycle helmet use aimed at relevant groups or individuals, it is possible to boost the share of voluntary helmet users (von Below 2016).

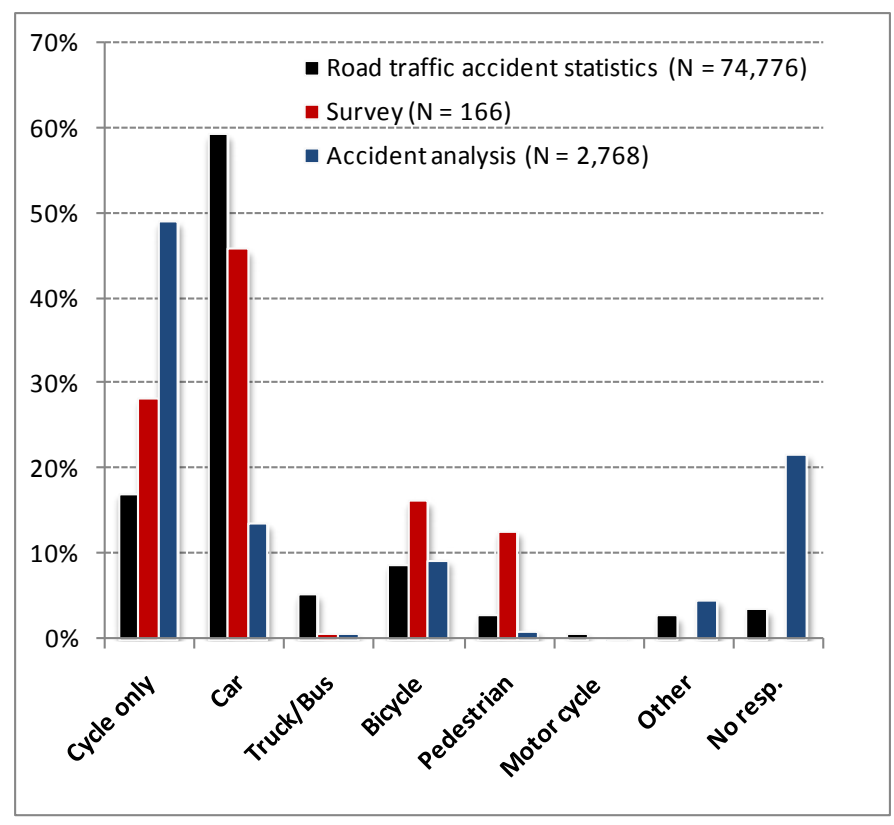

Figure 8: Distribution of the accident situation by cycleonly accident or other parties involved by different data source (von Below 2016).

The continuing increase of pedelecs can further promote and increase cycle use. Yet, only a few findings on who uses pedelecs, their behaviour, potential traffic safety problems and vehicle technology questions were available. As a result of the project "Potential influences of pedelecs on traffic safety with particular regard to older cyclists" (Alrutz et al. 2015) it became clear that pedelecs 25 are overwhelmingly used by those over the age of 60 , with many of them being over 70 . Few children and youths at this time use pedelecs. It has emerged that the behaviour of pedelec 25 riders - such as use of facility and behaviour in the junction - is comparable with the behaviour of those using conventional bicycles. Seniors with pedelecs 25 ride up 2 to $4 \mathrm{~km} / \mathrm{h}$ faster than seniors with conventional bicycles. The frequency and course taken by critical situations are comparable to those of conventional cyclists. The "Naturalistic Cycling Study" by Schleinitz et al. (2014) also demonstrated that users of pedelecs do not per se incur any higher or different safety risks than those using conventional bicycles.

In the behaviour factor research area, the following studies are envisaged for future BASt research: Establishing the determinants affecting route choice by cyclists, various groups of people, different cycle types (e.g. city bike, touring bike, mountain bike, pedelecs) and various user types (daily and leisure transportation).

It is, however, questionable if, and how significantly this excess of different measures and campaigns will impact traffic safety for cyclists. As things stand now, there are barely any studies evaluating the individual measures. For the development of new methods it will be necessary to know which methods succeed and which hold less promise.

\section{$\mathbf{5} .2$ Infrastructure area}

Traffic planning is based on the knowledge of given or relevant parameters. As part of the project titled "Extrapolations model of random sampling for cycling" (Schiller et al. 2011) an extrapolations model for short term counts of cycling traffic intensities was developed that can be deployed both in urban locales - major cities and small municipalities - as well as in rural areas or on touristic cycling paths. Cycling traffic intensities at metering points vary significantly by day, week, and year. In contrast to other kinds of traffic, such as motor vehicle traffic, these fluctuations are more pronounced under the influence of weather and time of year, but also depending on the often relatively low traffic intensities (as compared with motor vehicle traffic).

Cyclists illegally riding on the left are exposed to significantly more danger than cyclists riding on the right, especially at road junctions or access roads with high traffic volumes, because motor vehicles that must yield and are turning to enter do not expect cycle traffic from the right. In the study "Use of cycle 

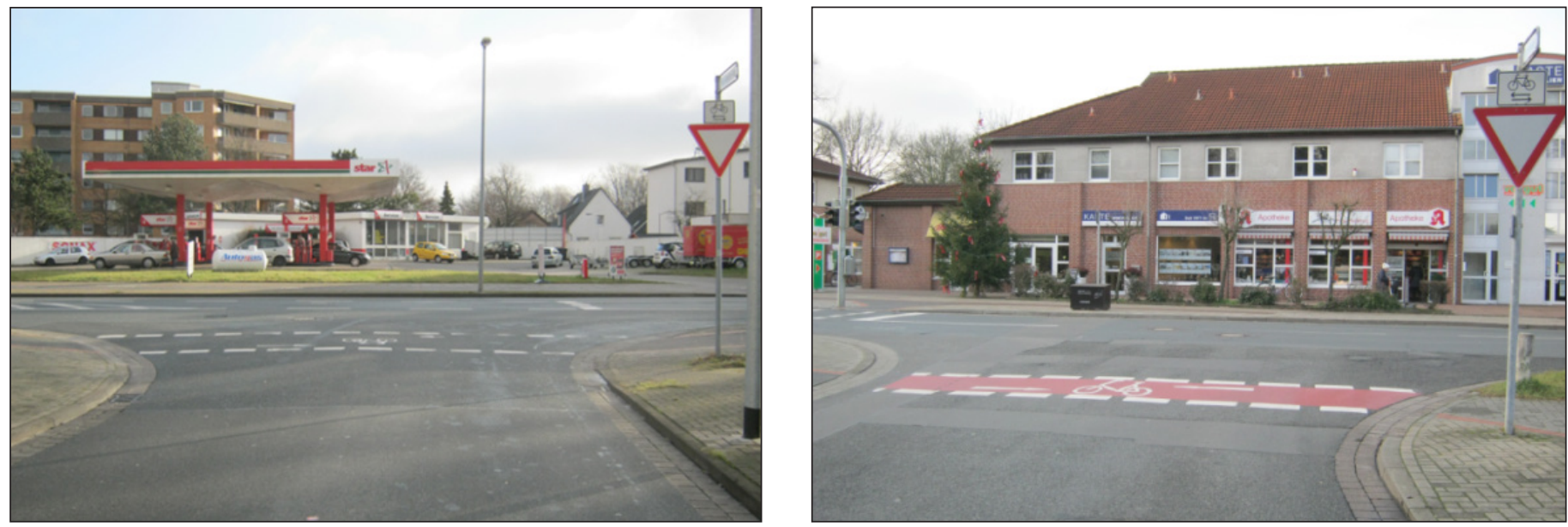

Figure 9: Examples of enhancing safety on two-way cycle paths with additional markings: cycling crossing with pictogram "bicycle" and marked with directional arrows; on the right, additional red coloration of a crossing (Alrutz et al. 2015).

paths in opposite direction - Improvements of safety" the focus was on the effect of various measures (e.g. see Figure 9) for safeguarding of cycle traffic on the left on two-way cycle paths (Alrutz et al. 2015). Results of the observations: Numerous motor vehicles turning in do not drive with the necessary caution when it comes to braking and eye contact at junctions and access roads. Unfavorable visibility conditions intensify the problem. Cyclists also lack risk awareness at T-junctions. The analysis shows that many cyclists use the left direction on the two-way cycle paths, but that many also illegally ride left on onedirectional cycle paths.

The average accident rate of illegally left-riding cyclists is about double than of cycling on the left on two-way cycle paths. The study concluded that urban cycle paths should only be opened in the opposite direction under exceptional conditions. Maintaining adequate visibility conditions is fundamental. The implementation of additional safety measures like pictograms or ideograms with directional arrows for cycle traffic, red coloration of cycle traffic crossings and, especially, structural measures - for example, cycle paths passages with effective ramps - can result in noticeable safety gains. The study suggested that on streets with heavy motor vehicle traffic and accordingly limited possibilities for crossing the roadway, closely-spaced crossing facilities can reduce illegal riding on the left. It also discussed the aspect of sensitizing cyclists to the danger of using the left direction (Alrutz et al. 2015).

According to the Guidelines for the Design of Rural Roads (RAL) 2012, cycle traffic is not to be permitted on roads in design class (EKL) 1 and EKL 2. However, for EKL 4 roads, cycling on the roadway is the standard solution. Especially for EKL 3 roads it has to be checked if cycle traffic can be mixed on the roadway or if, for reasons of traffic safety and traffic flow, it should be on a separate cycle path. According to RAL 2012, such a check must take into account the volume and speed of motor vehicle traffic, the percentage of heavy truck traffic, and the visibility condi-
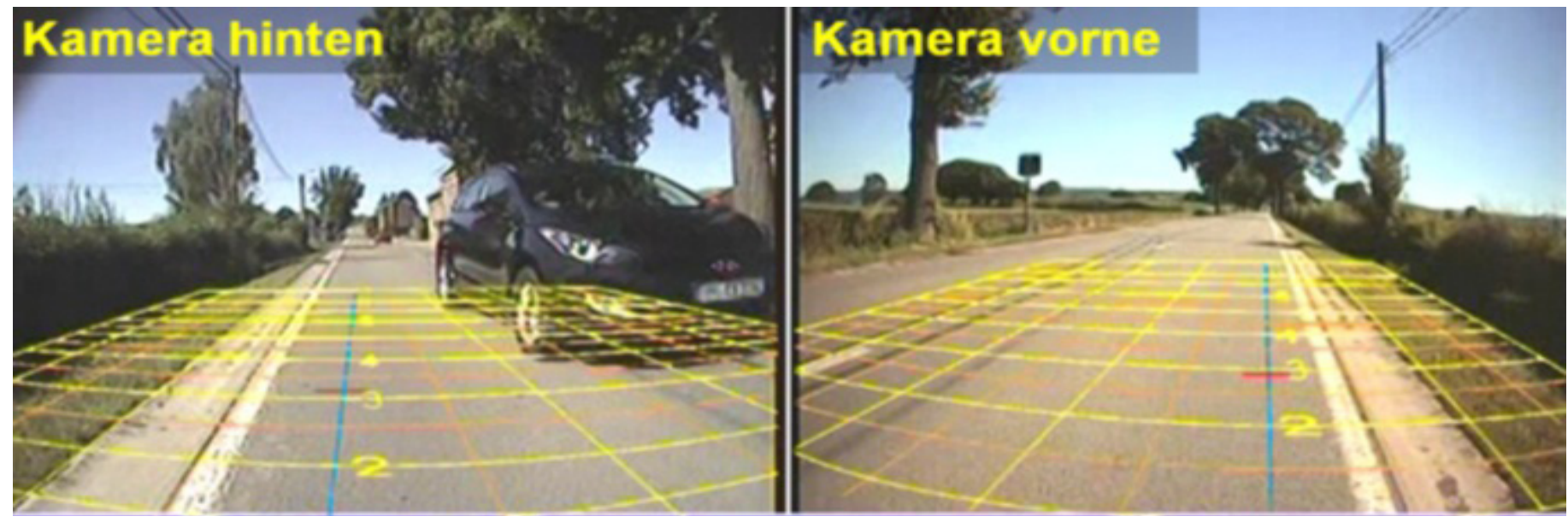

Figure 10: Video frames with rear-facing ("hinten") - and front ("vorne") camera perspectives and geometric grid (Baier et al. 2015). 
tions of the road as well as the volume of cycling traffic and the percentage of cyclists needing protection. RAL 2012 contains reference values for an evaluation which combinations of motor vehicle traffic volume and cycle traffic volume with "average" boundary conditions make roadway-accompanying sidewalks and cycle paths potentially advisable.

As part of the empirical investigation of the research project "Management of cycling on rural roads" (Baier et al. 2015) passing procedures of motor vehicles were recorded by measuring equipment which had been mounted on a pedelec 25 (see Figure 10). The results of the investigation confirmed the existing recommendations regarding priority rules for cycle traffic in RAL 2012. Because of the low number of accidents involving cycle traffic, it was not possibly to verify if roadway-contiguous channeling along open stretches of road offered possible safety advantages for cycle traffic. Hence, it remains an open question if advantageous (safe) cycle traffic mixing on the open road is juxtaposed with possible (safety) drawbacks in the adjoining junction.

Among others, BASt will in the future focus on the following research projects in the "infrastructure" area. The content and goal of the project "Effectiveness and utility of cycling infrastructure measures" will be the selection and assessment of methods for developing long-term safety impacts for measures designed to prevent accumulations of traffic accidents that are listed in the catalogue of measures against accident black spots.

For cycling as well as linkages between cycles and other means of transportation there remains a deep deficit in network design. However, a precondition for multimodal transport is a functional, optimized and safe cycling network. The need for generally-applicable recommendations for designing the cycling network has not stopped growing in recent years. Also, functional cycling networks are preconditions for keeping up with the increasingly fluid boundaries between public transport and individual transportation. Research focus is also on the traffic process at signalized junctions with high amounts of cycling traffic and on the heavily frequented cycle facilities between junctions. Along with this, the riding behaviour of cyclists that make up the transportation collective (pedelecs 25, cycle with trailer, children etc.) on highly-frequented, wide, straight cycling facilities is to be examined.

\subsection{Safety equipment and vehicle technology area}

The conflict between the truck making a right turn and the cyclist heading in the same direction assumes special importance and notoriety in traffic accidents particularly because of the high injury severity (many fatal accidents, see chapter 3.3). Aside from the accident investigation the question arises what structural and operational implementation at the junction provides the greatest degree of safety.

In the research project "Blind spot - conflict between right-turning truck and cycle riding straight" (Richter et al. 2014) design engineering, operational, and vehicle engineering measures were examined. Insights were gained into the sequence of events in the conflict situation or the situations leading up to the
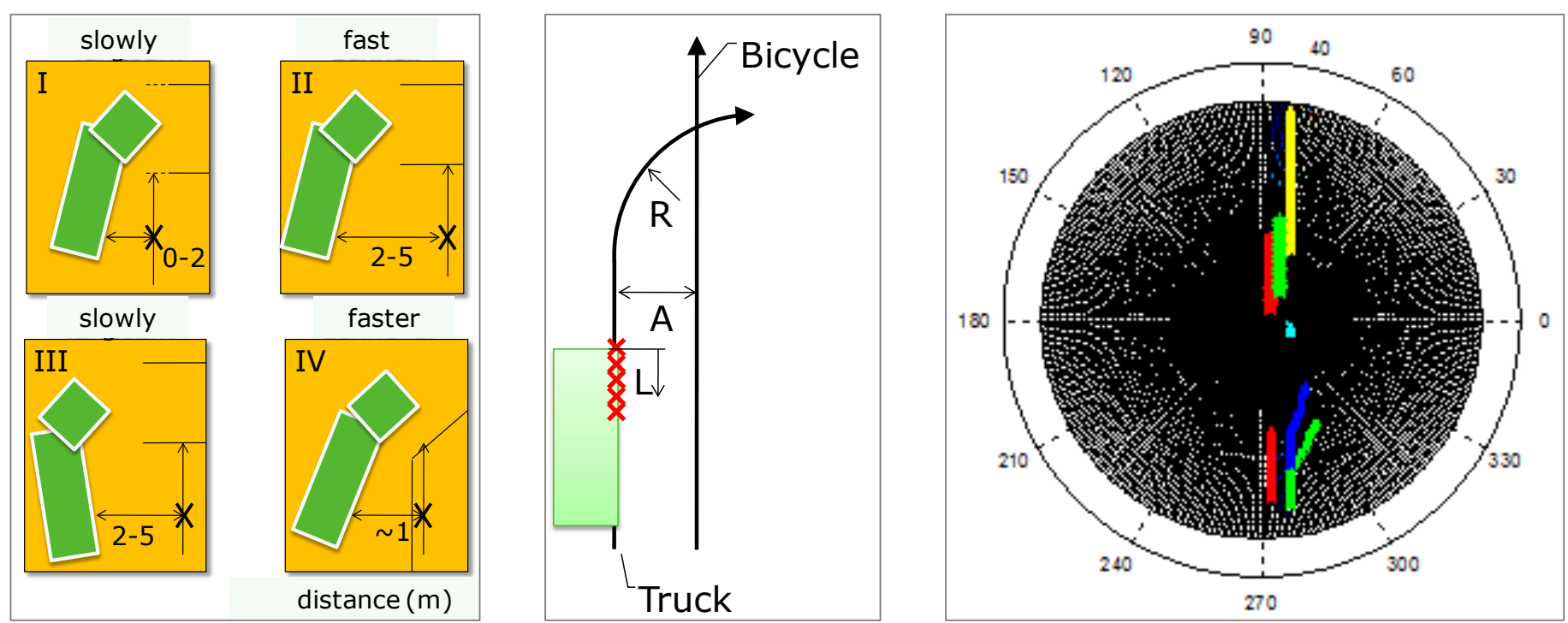

Figure 11: Overview of rough classification of scenarios, Sketch of relevant parameters and scenarios displayed in the range of aggregated cycle trajectories and tests tools (Schreck and Seiniger 2015). 
conflict and some recommendations were described for structural and operational features. However, it was not possible to derive workable recommendations for defusing the conflict situation through infrastructural measures.

At the present time, it is assumed that a turn assistance system would have a positive effect on the accident occurrence between right turning trucks and cycles. To foster appropriate system developments and also to be able to dictate the system's use once developed, will require specifications for the system requirements and suitable testing methods for rightturn assistance systems. Developing these requirements and feasible test procedures for the systems was the goal of the study "Driver assistance system for trucks" (Schreck and Seiniger 2015). Schreck and Seiniger analysed accident databases to identify relevant parameters during the conflict between truck and bicycle. Based on these parameters, simulations were carried out to define the necessary sensor field of view and implications from driving dynamics (see Figure 11). Test cases were defined and verified using custom and commercially available test tools. Based on the identified parameter space, the time required for a comfortable stop, and a suitable kinematic mod$\mathrm{el}$, it is possible to define the spatial areas around the truck in which a situational awareness system must be capable of detecting the cyclist and generating a timely information for the truck driver. Accidentology shows that the relevant accidents involve a truck and a bicycle first travelling at speeds up to $20 \mathrm{~km} / \mathrm{h}$ in the same direction, then the truck turning towards the bicycle. It is anticipated that at this stage only information-providing assistance systems are promising. Corresponding test scenarios have been defined and verified: test results of a prototype assistance system in the scenarios as well as an overview of the successfully used test tools were given. Results from this research project have been introduced into the rulemaking process in the UN-ECE which will be the base for a UN regulation for a blind spot driver assistance system for trucks to avoid blind spot accidents in the future.

Besides the improvement in cycling safety in the area of infrastructure and traffic participant behaviour, technical methods can also contribute to enhanced safety. These are also envisaged for future BASt research. Here we can identify new technologies or improve existing ones and evaluate their usefulness. The focus is not just supposed to be on technologies that apply directly to the bicycle (including the pedelec) but also other vehicles or infrastructure and personal equipment for the cyclist. Example of safety technologies in the above-mentioned areas are: braking equipment (including newer techniques like ABS) and optics technology for cycles (including pedelecs) as well as assist systems etc. for cycles or for other traffic participants.

\section{OUTLOOK}

The modal split shows an increase in cycling in Germany, especially in urban areas. The shift in choice of transportation to non-motorized vehicles can make a contribution to environmentally friendly mobility. This is especially so for urbanized spaces with their growing problems in meeting emissions limits. That said, however, it must be stated that cycling constitutes a slight percentage of the overall mileage and distances travelled. Pedelecs (electrically-assisted bicycles) can increase distances covered, but still only in a very limited area. Because of the expected further (local) growth in cycling's share as well as the societally- and politically-willed heightened attractiveness and promotion of cycling, further research activities will be necessary so as not to completely uncouple the development of cycling's traffic safety from the positive development of traffic safety overall. The comparison of the number of bicycle injury accidents with the total number of injury accidents in Germany indicates that user of bicycles have not benefited from the improvements in traffic safety in the same way than other road users have in the last 15-20 years. Thus, it is important to implement, among other things, safe cycling facilities.

The technical guidelines offer a wide range of safe cycling facility design and represent the state of the art. They are, however, in an ongoing process of revision to adapt ongoing changes and current developments. Input for the revision is, inter alia, the listed research projects of the Federal Highway Research Institute. But, besides the systematic application of the current technical guidelines for cycling infrastructure, it will be above all about improving the current road network inventory if the envisaged potential is to be realized. In cycling's case, if further improvements in traffic accident numbers are to be achieved, more areas than just infrastructural measures have to be focused on. So, for instance, the cyclists' traffic participant group and the behaviour of traffic participants must be studied even more intensely than they have been to date.

To promote cycling safety more effectively for further research activities the interdisciplinary coop- 
eration in the areas of behaviour, infrastructure, and safety equipment/vehicle technology is necessary. How sizeable the potential is for further reducing the number of fatalities in road traffic by enhanced traffic safety for the cyclist group has also been shown by the 2015 mid-term review of the BMVI's Traffic Safety Programme 2011. The challenge for cycling research is to find specific solutions for known problem areas, but also to anticipate unfavorable developments and, by deploying a suitable research bundle in these areas, find explanations and develop appropriate countermeasures. BASt's interdisciplinary safety research program is, among others, dedicated in a targeted fashion to the subject of the 2015 mid-term review of the 2011 traffic safety programme "Cycling safety on urban streets". The concept for the betterment of cycling safety on urban streets is composed of several research projects, with the aim of developing and validating measures in the areas of infrastructure (planning and design), traffic behaviours, and technology that can be used to further reduce issues related to cycling safety on urban streets.

\section{REFERENCES}

Alrutz, D., Bohle, W., \& Busek, S. (2015). Nutzung von Radwegen in Gegenrichtung - Sicherheitsverbesserungen [Use of cycle paths in opposite direction - Improvements of safety]. BASt Report V 261. Bergisch Gladbach. Retrieved from http://bast. opus.hbz-nrw.de/volltexte/2015/1610/pdf/V261_barrierefreies_Internet_PDF.pdf

Alrutz, D., Bohle, W., Hacke, U., Lohmann, G., \& Friedrich, N. (2015). Potenzielle Einfluesse von Pedelecs auf die Verkehrssicherheit [Potential influences of Pedelecs on road safety]. Report. Hannover und Darmstadt. Retrieved from http://edoc. difu.de/edoc.php?id=QLIFVXN7

Baier, R., Schuckließ, W., Jachtmann, Y., Diegmann, V., Mahlau, \& A., Gaessler, G. (2013). Radpotenziale im Stadtverkehr [Potentials of cycling in urban traffic]. BASt Report V 227. Bergisch Gladbach. Retrieved from http://bast.opus.hbz-nrw.de/ volltexte/2013/697/pdf/V227b.pdf

Baier, R., Leu, P., \& Rittershaus, J. (2015). Fuehrung des Radverkehrs an Landstraßen [Management of cycling on rural roads]. Report FE 21.0055/2013. Unpublished. Aachen.

Von Below, A. (2016). Verkehrssicherheit von Radfahrern Analyse sicherheitsrelevanter Motive, Einstellungen und Verhaltensweisen [Road safety of cyclists: Analysis of motives relevant for security, settings and behaviour patterns]. BASt Report M 264. Bergisch Gladbach. Retrieved from http://bast.opus. hbz-nrw.de/frontdoor.php?source_opus $=1663 \&$ la $=$ de

BMVI (2011). Road Safety Programme 2011. English Translation. Retrieved from http://www.bmvi.de/SharedDocs/
EN/Documents/LA/road-safety-programme-2011.pdf? blob=publicationFile

BMVI (2012). National Cycling Plan 2020. English Translation. Retrieved from http://edoc.difu.de/edoc.php?id=1u032rd6

BMVI (2015). Mid-Term Review of the 2011-2020 Road Safety Programme. English Translation. Retrieved from http://www. bmvi.de/SharedDocs/EN/publications/mid-term-review-of-the2011-2020-road-safety-programme.pdf? blob=publicationFile

European Commission. Statistics - accidents data. CARE. Retrieved from http://ec.europa.eu/transport/road_safety/specia$\underline{\text { list/statistics/index_en.htm }}$

Federal Statistical Office (2014). Verkehr - Verkehrsunfaelle, 2013 [Traffic - Traffic Accidents]. Retrieved from Federal Statistical Office: https://www.destatis.de/DE/Publikationen/Thematisch/TransportVerkehr/Verkehrsunfaelle

Federal Statistical Office (2016). Verkehr - Verkehrsunfaelle, 2015 [Traffic - Traffic Accidents]. Retrieved from Federal Statistical Office: https://www.destatis.de/DE/Publikationen/Thematisch/TransportVerkehr/Verkehrsunfaelle

Follmer, R. (2011). Mobilitaet in Deutschland - Fahrradnutzung [Mobility in Germany - Bicycle use]. Presentation. Retrieved from http://www.mobilitaet-in-deutschland.de/pdf/MiD_2008_ Fahrrad_Impulsvortrag.pdf

Follmer, R., Kunert, U., Kloas, J.,\& Kuhfeld, H. (2004). Mobilitaet in Deutschland 2004 [Mobility in Germany]. Bonn and Berlin. Retrieved from http://www.mobilitaet-in-deutschland. de/pdf/ergebnisbericht_mid_ende_144_punkte.pdf

Follmer, R., Gruschwitz, D., Jesske, B., Quand, S., Lenz, B., Nobis, C., Köhler, K., Mehlin, M. (2010). Mobilitaet in Deutschland [Mobility in Germany] 2008. Bonn und Berlin. Retrieved from http://www.mobilitaet-in-deutschland.de/pdf/MiD2008_ Abschlussbericht_I.pdf

German Road and Transportation Research Association (FGSV 2010). Empfehlungen für Radverkehrsanlagen (ERA) [Recommendations for cycle facilities]. Cologne.

German Road and Transportation Research Association (FGSV 2012). Guidelines for the Design of Urban Roads 2006 (RASt 2006). Edition 2006 - English Translation 2009.

German Road and Transportation Research Association (FGSV 2013). Richtlinien für die Anlage von Landstraßen (RAL 2012) [Guidelines for the design of rural roads]. Cologne.

Huetter, A. (2013). Verkehr auf einen Blick [Traffic of one view]. Federal Statistical Office. Wiesbaden. Retrieved from https://www.destatis.de/DE/Publikationen/Thematisch /TransportVerkehr/Querschnitt/BroschuereVerkehrBlick0080006139004.pdf? blob=publicationFile

Institute for Applied Social Science Research (INFAS) and the Institute of Transport Research of the German Aerospace Center (DLR) (2010). Mobilitaet in Deutschland 2008 [Mobility in Germany]. Bonn and Berlin.

Richter, T., Karrer-Gauß, K., Sachs, J., Schreiber, A., Schreiber, M. (2014). Toter Winkel - Konflikt zwischen rechtsabbiegenden Lkw und geradeausfahrendem Radverkehr [Blind spot Conflicts between right turning trucks and straight on going bicycles], Report FE 82.512/2010. Unpublished. Berlin. 
Schleinitz, K., Franke-Bartholdt, L., Petzoldt, T., Schwanitz, S., Gehlert, T., \& Kuehn, M. (2014). Pedelec-Naturalistic Cycling Study. German Insurers Accident Research. Berlin. Retrieved from http://udv.de/de/publikationen/forschungsberichte/pede lec-naturalistic-cycling-study

Schiller, C., Zimmermann, F., \& Bohle, W. (2011). Hochrechnungsmodell von Stichprobenzaehlungen für den Radverkehr [Extrapolations model of random sampling for cycling]. Dresden. Retrieved from http://www.forschungsinformationssystem. de/servlet/is/375673/

Schreck, B., \& Poeppel-Decker, M. (2014). Unfallgeschehen zwischen rechtsabbiegenden Gueterkraftfahrzeugen und geradeausfahrenden Radfahrern [Accident occurrence between trucks turning right and cyclists riding straight]. Report. Bergisch Gladbach.

Schreck, B., \& Seiniger, P. (2015). Abbiege-Assistenzsystem für Lkw [Driver assistance system for trucks]. BASt Report F 104. Bergisch Gladbach. Retrieved from http://bast.opus.hbz-nrw. de/frontdoor.php?source_opus=1222\&la=de 